\title{
HOM ABSORBER FOR THE KEKB NORMAL CONDUCTING CAVITY
}

\author{
Y. Takeuchi, K. Akai, N. Akasaka, E. Ezura, T. Kageyama, F. Naito, T. Shintake, \\ and Y. Yamazaki \\ KEK, National Laboratory for High Energy Physics, 1-1 Oho, Tsukuba, Ibaraki, 305 JAPAN
}

The HOM absorber for the normal conducting RF cavity of the KEK B-factory (KEKB) was designed. Sixteen bulletshape sintered $\mathrm{SiC}$ (silicon carbide) ceramics are used for HOM absorption. The HOM power to be handled will be about $10 \mathrm{~kW}$ per cavity, corresponding to about $1 \mathrm{~kW}$ per absorber. A prototype of $\mathrm{SiC}$ absorber was made to verify the performance as a HOM absorber in vacuum. The high power test was carried out successfully using a pulsed klystron ( $\mathrm{f}=1296 \mathrm{MHz}$ ). The design of the HOM absorber and the results of the high power test are discussed.

\section{INTRODUCTION}

A prototype of normal conducting cavity for KEKB has been designed and built [1]. This prototype cavity is loaded with a coaxial waveguide for damping higher order modes (HOM's). The waveguide is equipped with a notch filter. Figure 1 shows a schematic drawing of this cavity. For HOM absorption, sixteen bullet-shape sintered $\mathrm{SiC}$ ceramics are inserted from the end of the coaxial waveguide. The absorber dimensions are $40 \mathrm{~mm}$ in diameter, and $400 \mathrm{~mm}$ in total effective length including a 100-mm nosecone section. Each $\mathrm{SiC}$ absorber has a cooling water channel bored inside and is directly cooled. The HOM power (at frequencies around 1 $\mathrm{GHz}$ ) to be handled will be on the order of $\sim 10 \mathrm{~kW}$ per cavity, corresponding to $\sim 1 \mathrm{~kW}$ per absorber.

Some reasons why we have chosen $\mathrm{SiC}$ ceramics are as follows: 1) $\mathrm{SiC}$ is a fine and dense ceramics which has a high mechanical strength and a low outgassing rate, and is chemically inert. 2) $\mathrm{SiC}$ has a relatively high thermal conductivity of $\sim 120 \mathrm{~W} / \mathrm{mK}$ at room temperature, which is about one half of that of Aluminum $(230 \mathrm{~W} / \mathrm{mK})$. 3) At the

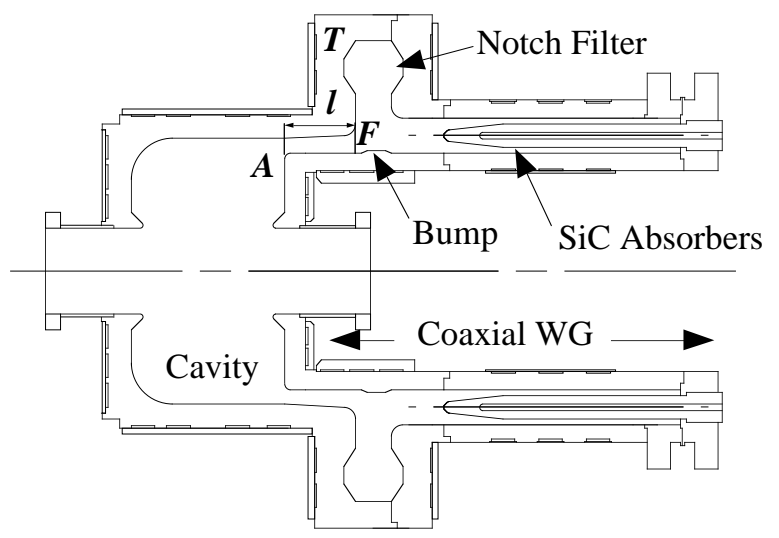

Figure 1: A schematic drawing of the test cavity.
2.5-GeV electron linac in $\mathrm{KEK}$, nearly two hundred $\mathrm{SiC}$ absorbers (diameter $=24 \mathrm{~mm}$, length $=300 \mathrm{~mm}$ ) have been used for the S-band waveguide loads without any troubles for about ten years. A prototype of S-band $\mathrm{SiC}$ absorber was tested up to a peak power of $10 \mathrm{MW}$ with a pulse width of $3.5 \mu \mathrm{sec}$ at $50 \mathrm{~Hz}$, corresponding to a average power of 1.75 $\mathrm{kW}$ [2]. Among these reasons, the third one most encouraged us to use $\mathrm{SiC}$ ceramics.

\section{HOM ABSORBERS}

\section{A. Permittivity of $\mathrm{SiC}$}

We measured the complex permittivities of several $\mathrm{SiC}$ samples and selected an $\alpha$-type $\mathrm{SiC}$ ceramics [3]. Figure 2 shows the frequency response of the dielectric constant $\varepsilon^{\prime}$ and the loss tangent of the $\mathrm{SiC}$ ceramics, measured using a dielectric probe kit (HP85070B).

The permittivity of the SiC ceramics is sensitive to production conditions such as sintering temperature, contamination of furnace atmosphere and so on. Many products of $\mathrm{SiC}$ ceramics are usually used for mechanical parts such as a bearing. The electric properties are not usually specified. Therefore, we must pay attention to the reproducibility of the electric properties of the $\mathrm{SiC}$ ceramics. We measured the permittivity of $\mathrm{SiC}$ ceramics of different lots for the HOM absorbers. We confirmed that the $\mathrm{SiC}$ ceramics, sintered in the same furnace, have almost the same permittivity. Further studies are being continued to control the permittivity.

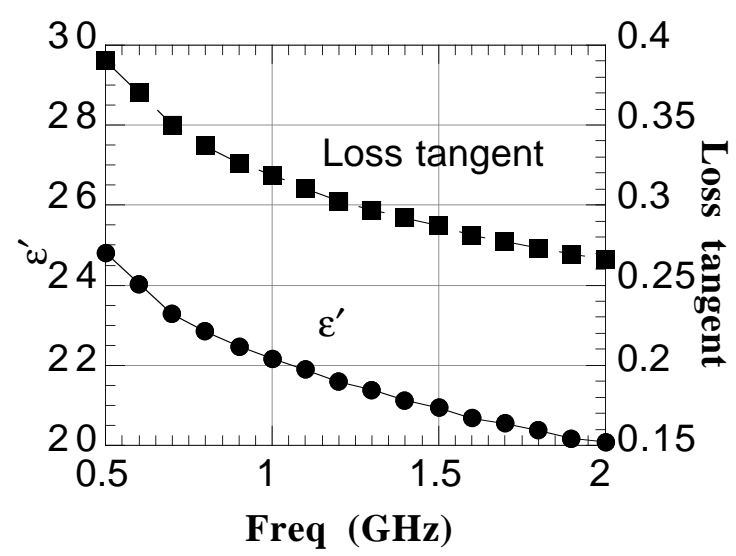

Figure 2: The dielectric constant and loss tangent of the $\mathrm{SiC}$ ceramics are plotted as a function of frequency. 


\section{B. Vacuum Seal Methods}

We designed two types of $\mathrm{SiC}$ absorbers for the prototype cavities. One of them (model A) has a vacuum seal structure using a metal o-ring and the other (model B) has a metal sleeve directly brazed to the $\mathrm{SiC}$ ceramics. Figure 3 shows a schematic drawing of model B. Figures 4 and 5 show the vacuum seal structures of these models.

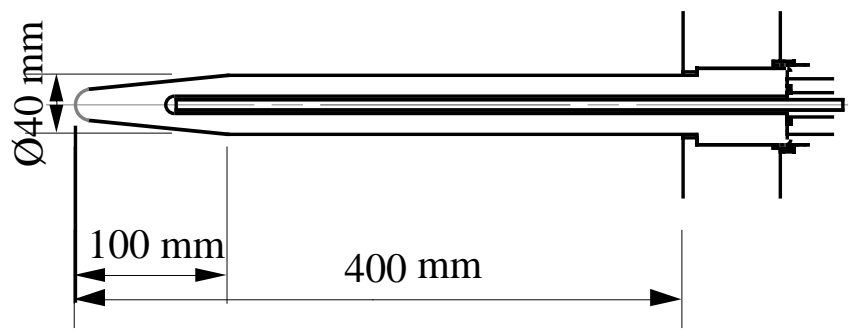

Figure 3: A schematic drawing of the model B absorber.

Since the structure of model A is simple and easy to fabricate, we employed model A for the first prototype cavity. A vacuum test was carried out using a test set with the same sealing structure. Heat-cycle test $\left(15 \sim 80{ }^{\circ} \mathrm{C}\right)$ was also carried out about ten times. No vacuum leak was detected. However, we had some leak trouble when SiC absorbers were installed in the first prototype cavity. We are planing to further vacuum test of this structure to optimize the surface roughness of the $\mathrm{SiC}$ ceramics for better vacuumseal performance.

The absorbers of model B, which will be installed in the second prototype cavity, was designed for more reliable vacuum tightness in the long term operation. A copper thin sleeve was directly brazed to the $\mathrm{SiC}$ ceramics. Generally, brazing the $\mathrm{SiC}$ ceramics with a metal is a very difficult technique. Some reasons are as follows: 1) Since the coefficient of thermal expansion of the $\mathrm{SiC}$ ceramics (4.2x10-6/ $\left./{ }^{\circ} \mathrm{C}\right)$ is much smaller than those of metals (for copper it is $16.6 \times 10-6 /{ }^{\circ} \mathrm{C}$ ), large stress at the braze joint develops in cooling process of the brazing. 2) By the reaction between the $\mathrm{SiC}$ ceramics and the brazing alloy (such as $\mathrm{Cu}$ -

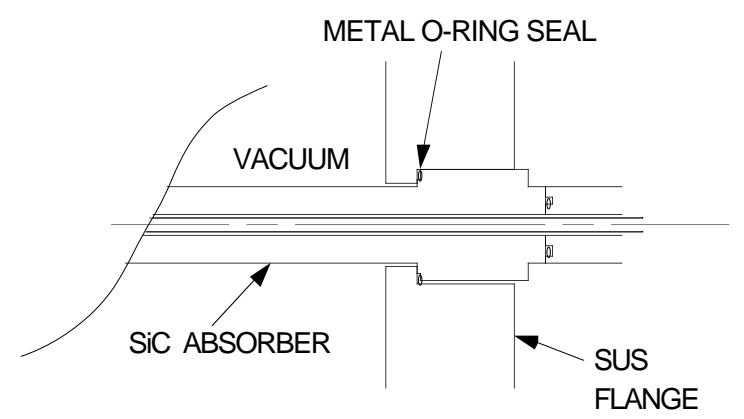

Figure 4: A SiC absorber using a metal o-ring for the vacuum seal.
$\mathrm{Ag}$-Ti), some fragile alloys are usually produced, and makes the braze joint weak.

A stable brazing between the $\mathrm{SiC}$ ceramics and the copper sleeve was developed by a supplier [4]. This technique was applied to the model B. Test pieces of model B passed more than 500 heat cycles $\left(-30 \sim 180{ }^{\circ} \mathrm{C}\right)$ [5].

Figure 6 shows a prototype of the model B absorber, which will be installed in the second prototype cavity.

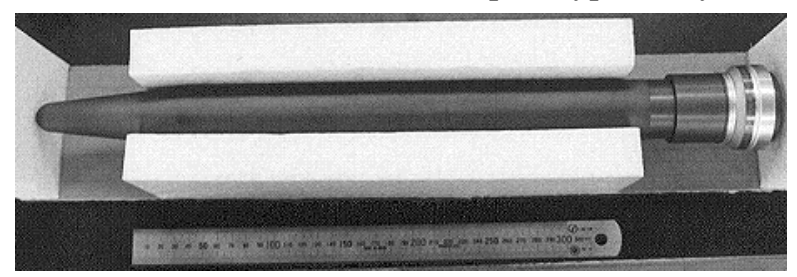

Figure 6: A prototype of the model B absorber.

\section{HIGH-POWER TEST}

A prototype $\mathrm{SiC}$ absorber of model $\mathrm{A}$ was made to verify the performance as a HOM absorber in vacuum. Figure 7 shows the layout of the high power test. The prototype absorber was inserted from the end of an L-band rectangular waveguide (WR650), where the standing-wave ratio VSWR was measured $\sim 1.1$. The vacuum pressure was about $10^{-10} \sim 10^{-9}$ Torr after a 64 -hour baking at $80^{\circ} \mathrm{C}$. The high power test was carried out using a pulsed klystron ( $f=$ $1296 \mathrm{MHz}$ ) up to a peak power of $128 \mathrm{~kW}$ with a pulse width $540 \mu \mathrm{sec}$ at $50 \mathrm{~Hz}$, corresponding to a average power of $\sim 3.5 \mathrm{~kW}$. The prototype absorber functioned normally without any vacuum, thermal, or discharge trouble up to 2.5 $\mathrm{kW}$ of average RF power. However, the vacuum pressure increased gradually $\left(10^{-9} \sim 10^{-8}\right.$ Torr) over $2.5 \mathrm{~kW}$. This is due to the temperature rise at the nosecone tip of the $\mathrm{SiC}$ absorber, which was roughly estimated about $100{ }^{\circ} \mathrm{C}$ at 2.5 $\mathrm{kW}$. This $\mathrm{SiC}$ absorber would handle much higher average power than $2.5 \mathrm{~kW}$ if either cooling water is led near the nosecone tip or the absorber is baked enough at a higher temperature.

The outgassing rate of the $\mathrm{SiC}$ ceramics was also

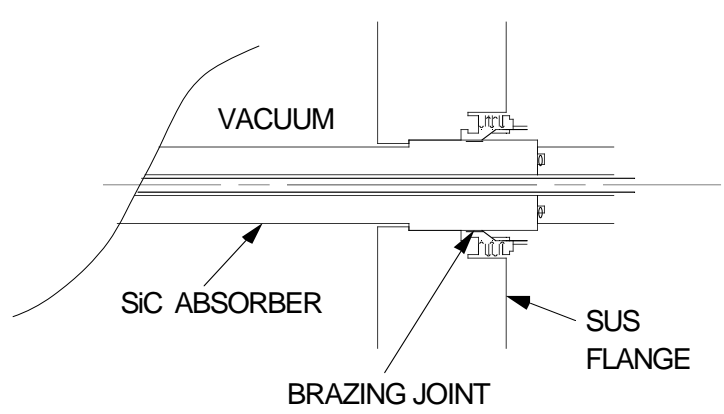

Figure 5: A SiC absorber using a brazing joint. The $\mathrm{SiC}$ ceramic is directly brazed to a copper sleeve. 
measured using a cylindrical sample (diameter $=50 \mathrm{~mm}$, height $=50 \mathrm{~mm}$ ). After 24 -hour baking at $150{ }^{\circ} \mathrm{C}$, the outgassing rate at room temperature was $3 \times 10^{-12}$ Torr $1 / \mathrm{s}$ $\mathrm{cm}^{2}$.

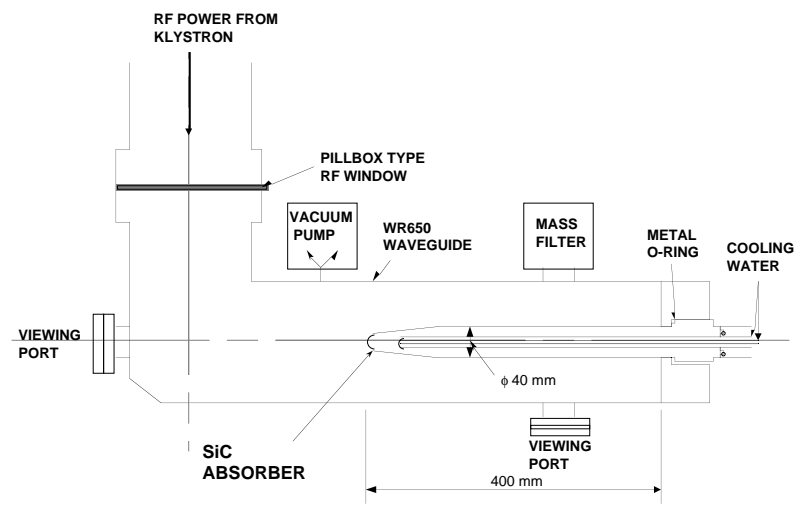

Figure 7: The layout of the high power test.

\section{CONCLUSION}

Two types of HOM absorbers made of SiC ceramics were designed. One of them has a vacuum seal structure using a metal o-ring and the other has a metal sleeve directly brazed to the $\mathrm{SiC}$ ceramics. A prototype, which used a metal o-ring, was made to verify the performance as a HOM absorber in vacuum. High power test was carried out successfully. This prototype absorber handled up to the average power of $2.5 \mathrm{~kW}$, which satisfies the requirement of the absorber. Higher average power than $2.5 \mathrm{~kW}$ would be handled by improving the water cooling circuit in the nosecone.

\section{ACKNOWLEDGMENTS}

We would like to thank H.Hisamatsu for measuring the vacuum properties of the $\mathrm{SiC}$ sample

\section{REFERENCES}

[1] T.Kageyama et al., "Development of a HOM-Damped Cavity for the KEK B-Factory (KEKB)", WPQ17 in this conference.

[2] H.Matsumoto et al., "Application of SiC Ceramics for Microwave Absorber", Proc. 9th Linear Accelerator Meeting in Japan, Kyoto, 1984, pp. 124-126.

[3] supplied by Hitachi Kasei Ceramics Co., Ltd.

[4] The brazing technique was developed by Hitachi Haramachi Electronics Co., Ltd.

[5] Private communication with T. Oku, Hitachi Haramachi Electronics Co., Ltd. 